\title{
A SIMPLE METHOD FOR MEASURING $\mathrm{CO}_{2}$ IN A CONTINUOUS AIR-FLOW SYSTEM: MODIFICATIONS TO THE SUBSTRATE-INDUCED RESPIRATION TECHNIQUE
}

\author{
Weixin Cheng* and David C. Coleman \\ Institute of Ecology, University of Georgia, Athens, GA 30602, U.S.A.
}

(Accepred 5 November 1988)

\begin{abstract}
Summary-A simple, inexpensive method for measurement of respiration $\left(\mathrm{CO}_{2}\right.$ evolution) under a continuous air-flow was calibrated against an i.r. gas analyzer. Regression equations were developed to apply the method to general soil respiration measurement in the laboratory. The substrate-induced respiration technique was modified. By using $120 \%$ FWHC as a standard soil water condition during incubation, initial substrate-induced maximal respiration was measured in an optimal fashion. The problem of high experimental errors associated with soils with high $\mathrm{pH}$ values $(\mathrm{pH}>6.5)$ can be avoided by using the simple method of $\mathrm{CO}_{2}$ measurement with this continuous air-flow system.
\end{abstract}

\section{INTRODLCTION}

A variety of methods exist to estimate microbial biomass in soil (Jenkinson and Ladd, 1981). Of these methods. one of the simplest and most rapid is the substrate-induced respiration (SIR) technique, where glucose induces a maximal respiratory response from the soil microbial biomass, measured as $\mathrm{CO}_{2}$ evolution, and relates this response to biomass $\mathrm{C}$ ( $\mathrm{An}$ derson and Domsch, 1978). However, there are several technical problems associated with the original method. First of all, this method was restricted to soil samples with a narrow moisture range; therefore it is difficult to apply this method to field samples. Secondly, the non-continuous flushing of the "Wosthoff Ultragas 3" $\mathrm{CO}_{2}$-analyzer (Wosthoff Co., F.R.G.) used by Anderson and Domsch (1978) is also subject to a large experimental error, especially when the $\mathrm{pH}$ value of the soil sample is higher than 6 (Martens, 1987). Modifications have been made by West and Sparling (1986) to the original method in order to solve the sample moisture problem by incubating soil samples in the form of a soil suspension with a ratio of $2 \mathrm{ml}$ water to $1 \mathrm{~g}$ equivalent oven-dry weight of soil. This modified method still has problems with soil samples which have $\mathrm{pH}>6$.

We propose a simple method to measure $\mathrm{CO}_{2}$ in a continuous air-flow system (CAFS) and an improvement to the SIR technique.

\section{MATERIALS AND METHODS}

\section{Description of the method}

A continuous aeration apparatus is illustrated in Fig. 1. $\mathrm{CO}_{2}$-free air is generated by an aquarium air pump, passing air through a strongly alkaline solution (1 or $2 \mathrm{M} \mathrm{NaOH}$ ) via an air stone (Aqua-Mist Cylinder $11 \mathrm{~mm}$, Cat. No. AS-6, Penn-Plax Inc.

-To whom all correspondence should be addressed.
U.S.A.) at the bottom of the column. The soil sample in the incubation flask is flushed continuously at a predetermined air-flow rate. The $\mathrm{CO}_{2}$ evolved from the soil sample is carried to the air stone at the bottom of the final $\mathrm{CO}_{2}$ trap, which is a test tube $(2.5 \mathrm{~cm}$ i.d. $\times 25 \mathrm{~cm})$ containing $50.0 \mathrm{ml}$ of $\mathrm{NaOH}$ solution of known molarity. After a period of exposure the final $\mathrm{CO}_{2}$ trap is carefully removed and capped with a rubber stopper. Before titrating, excess $\mathrm{BaCl}_{2}$ in solution is added to the final trap to precipitate carbonate. The $\mathrm{NaOH}$ in the final trap is then titrated with $20 \mathrm{mM} \mathrm{HCl}$ using phenolphthalein as an indicator. The amount of $\mathrm{CO}_{2}$ evolved is calculated from the difference in $\mathrm{HCl}$ consumption between the soil sample and the blank (an empty incubating flask).

\section{Calibration of the method}

The trapping efficiency of this apparatus was calibrated using an i.r. gas analyzer (IRGA; Type 225 MK 3, The Analytical Development Co., England). Percentage $\mathrm{CO}_{2}$ loss after trapping was measured following the procedure of Edwards (1982). In the calibration, three rates of air-flow $(20,50$ or $80 \mathrm{ml} \mathrm{min}^{-1}$ ) controlled by needle valves and measured by an air flowmeter, three different $\mathrm{NaOH}$ concentrations in the final trap $(10,20$ or $30 \mathrm{~mm})$ and 10 different $\mathrm{CO}_{2}$ flow rates (from 0.26 to $2.0 \mathrm{mg} \mathrm{h}^{-1}$ ) generated by varying the amount of soil in the incubating flasks, were employed. 26 combinations out of the total 90 possible ones $(3 \times 3 \times 10=90)$ were tested. The resulting data were analyzed using multivariate linear regression after an arc-sine transformation of the square root of the percentage $\mathrm{CO}_{2}$ loss, which served as the dependent variable. The independent variables were $\mathrm{CO}_{2}$ evolution rate $\left(\mathrm{mg} \mathrm{h}^{-1}\right)$, air-flow rate $\left(\mathrm{ml} \mathrm{min}^{-1}\right)$ and molarity of $\mathrm{NaOH}$ in the final trap.

Another experiment was carried out in order to assess the time required for the establishment of a 


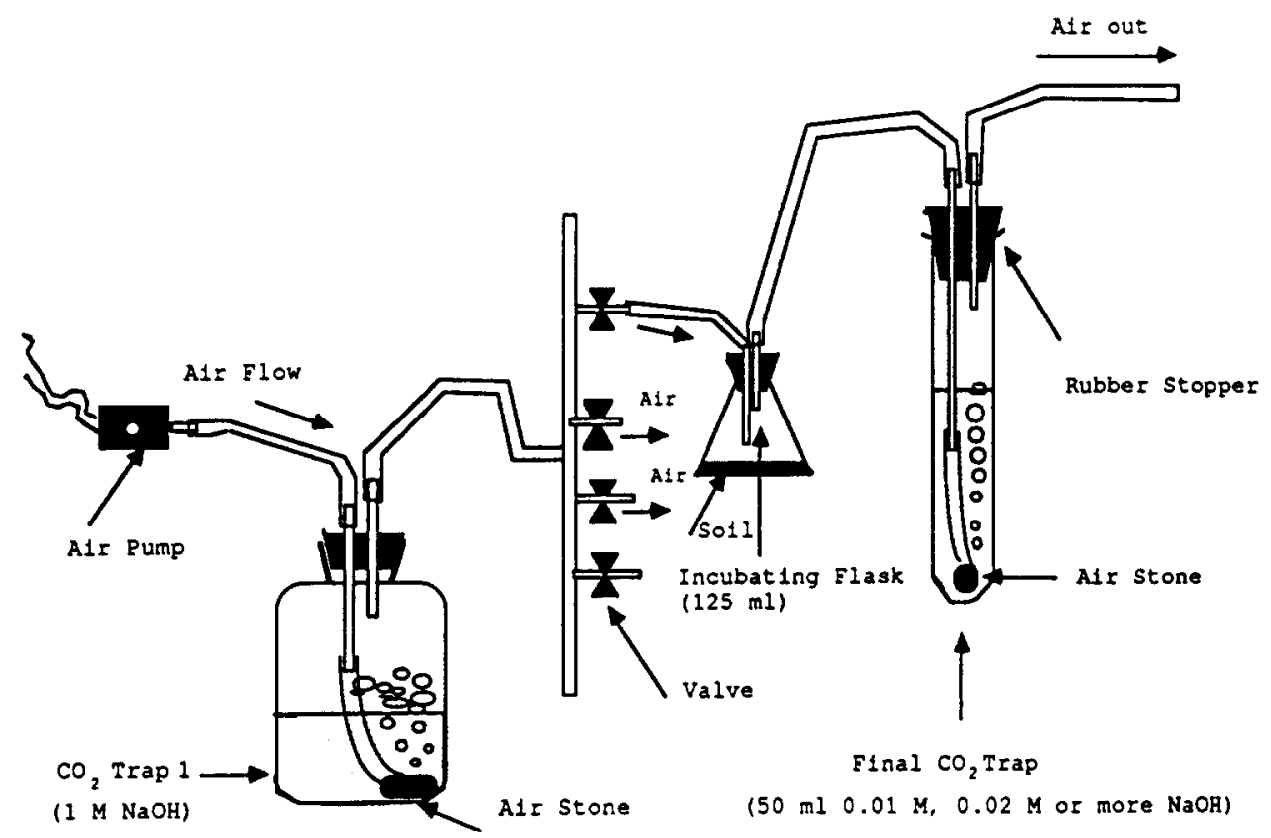

Fig. 1. Simple $\mathrm{CO}_{2} \cdot$ measuring apparatus with a CAFS.

stable $\mathrm{CO}_{2}$ output rate in the CAFS under different air-flow rates. Three air-flow rates were pre-set in replicates of three. Homogenized soil $(20 \mathrm{~g})$ with $15 \% \mathrm{w} / \mathrm{w}$ water content was put into each incubation flask and $3.5 \mathrm{ml}$ of glucose solution was uniformly added by a syringe into each soil-contained flask. A final water content of $35 \% \mathrm{w} / \mathrm{w}$ and a glucose concentration of $8 \mathrm{mg} \mathrm{g}^{-1}$ of oven-dry soil were achieved. The $\mathrm{CO}_{2}$ testing procedure was the same as described above in the calibration section.

\section{The effect of soil moisture on SIR}

The soil used was taken from the University of Georgia Horseshoe Bend Experimental Area on the Georgia Piedmont. The soil is a Hiwassee series (clayey, kaolinitic, thermic, Rhodic Kandudult, $2.3 \% \mathrm{C}, 0.19 \% \mathrm{~N}, \mathrm{pH} 6.5$ ), a well-drained sandy clay loam found on $0-2 \%$ slopes (Groffman, 1985). The soil was sampled from the $0.5 \mathrm{~cm}$ layer 2 days before the test, sieved $(<2 \mathrm{~mm})$, homogenized and stored in a refrigerator. Before the start of the experiment, soil samples were equilibrated to room temperature $\left(22 \pm 1^{\circ} \mathrm{C}\right)$.

Seven levels of soil water content $(14.6,20.4,29.2$, $35.0,43.8,49.6$ or $200.0 \% \mathrm{w} / \mathrm{w}$ ) and two methods of glucose addition [dry addition-Anderson and Domsch (1978); wet addition-West and Sparling (1986)], all in three replicates, were employed in the experiment. A $30 \mathrm{~g}$ sample of homogenized field moist soil was used for each treatment except for the $200 \% \mathrm{w} / \mathrm{w}$ treatment in which $10 \mathrm{~g}$ of the same soil was used for each replicate. The original soil water content was $8.7 \% \mathrm{w} / \mathrm{w}$. The amount of water to be added to each treatment was calculated based on the original soil water content and the final soil moisture needed. Based on the results from an experiment with the same soil (Fig. 2), an addition of $8 \mathrm{mg}$ glucose $\mathrm{g}^{-1}$ oven-dry soil was applied to each treatment either according to the procedure described by Anderson and Domsch (1978) or by West and Sparling (1986) except for the highest soil water content $(200 \% \mathrm{w} / \mathrm{w})$, in which a glucose concentration of $30 \mathrm{mg} \mathrm{ml}^{-1}$ of soil water (recommended by West and Sparling, 1986) was used. All samples were analyzed using the CAFS method described above. A $10 \mathrm{~mm} \mathrm{NaOH}$ solution was used and the trapping period was between 0.5 and $2.5 \mathrm{~h}$ after glucose addition. All values of SIR were presented as $\mathrm{mg} \mathrm{CO} 100 \mathrm{~g}^{-1}$ oven-dry soil $\mathrm{h}^{-1}$.

\section{RESULTS AND DISCUSSION}

\section{Evaluation of the method}

The regression equation obtained from the calibration study is as follows:

$$
\begin{array}{r}
Y=10.702+0.07 X_{1}-295.7 X_{2} \\
+0.605 X_{3} \quad(P<0.001) .
\end{array}
$$

Its confidence interval is

$$
P\{Y \pm 3.88\}=0.95 \text {, }
$$

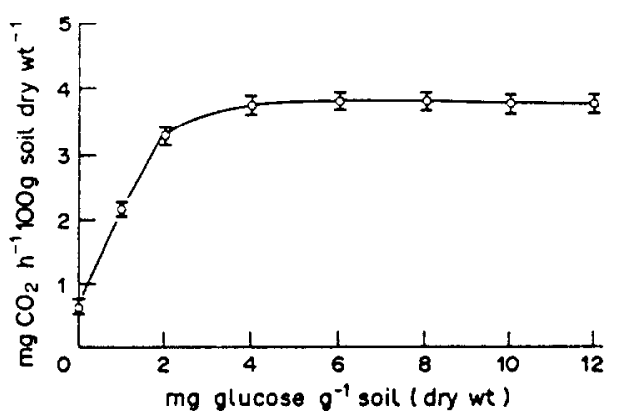

Fig. 2. The effect of different rates of glucose addition on the SIR of the Horseshoe Bend soil $(0-5 \mathrm{~cm}$ layer) with a $35 \% \mathrm{w} / \mathrm{w}$ soil water content during the incubation. Bars are $\pm 1 \mathrm{SE}$. 
where

$$
\begin{aligned}
Y & =\text { arcsin of the square root of } \% \mathrm{CO}_{2} \text { loss, } \\
X_{1} & =\text { air-flow rate }\left(\mathrm{ml} \mathrm{min}^{-1}\right), \\
X_{2} & =\mathrm{NaOH} \text { molarity in the final trap } \\
X_{3} & =\mathrm{CO}_{2} \text { evolution rate }\left(\mathrm{mg} \mathrm{h}^{-1}\right) .
\end{aligned}
$$$$
\text { and }
$$

The regression coefficient associated with each independent variable was evaluated by a $t$-test. The results indicate that the $\mathrm{CO}_{2}$ evolution rate $\left(X_{3}\right)$ does not have significant influence on the $\mathrm{CO}_{2}$ percentage loss $(P>0.4)$. This implies that the apparatus can be used over a wide range of $\mathrm{CO}_{2}$ evolution rates. The other two variables significantly affect the trapping efficiency. For the purpose of prediction, a second regression was developed with only two variables, air-flow rate and $\mathrm{NaOH}$ concentration. The second regression equation is

$$
\begin{array}{r}
Y=11.009+0.0754 X_{1} \\
-291.585 X_{2} \quad(P<0.001) .
\end{array}
$$

Its confidence interval is

$$
P\{Y \pm 3.86\}=0.95
$$

where $Y, X_{1}$ and $X_{2}$ are the same as in equation (1).

This analysis indicated that the most important controlling variable on trapping efficiency is $\mathrm{NaOH}$ concentration in the final trap (coefficient = $-291.585 ; P<0.001$ ). However, the $\mathrm{NaOH}$ concentration also determines how large the experimental error will be due to titration and handling. In general, 10 or $20 \mathrm{~mm}$ seems to be the most acceptable concentration for most soils (percentage $\mathrm{CO}_{2}$ loss is usually $<5 \%$ ). Based on our experience, $\mathrm{NaOH}$ concentration in the final trap should never be $<8 \mathrm{mM}$.

Air-flow rates not only significantly $(P<0.01)$ influence the $\mathrm{CO}_{2}$ trapping efficiency of the apparatus, but also influence the time required for the establishment of a stable $\mathrm{CO}_{2}$ output rate in the CAFS (Fig. 3). For air-flow rates of 50 and $80 \mathrm{ml} \mathrm{min}^{-1}$, the system can reach a stable $\mathrm{CO}_{2}$ output rate in $<30 \mathrm{~min}$. However, at an air-flow rate of $10 \mathrm{ml} \mathrm{min}^{-1}$ the system does not reach the stable $\mathrm{CO}_{2}$ rate until about $2 \mathrm{~h}$ after glucose addition. It should be noted that the initial maximum $\mathrm{CO}_{2}$ evolution rates for the soil used here are very stable during the period

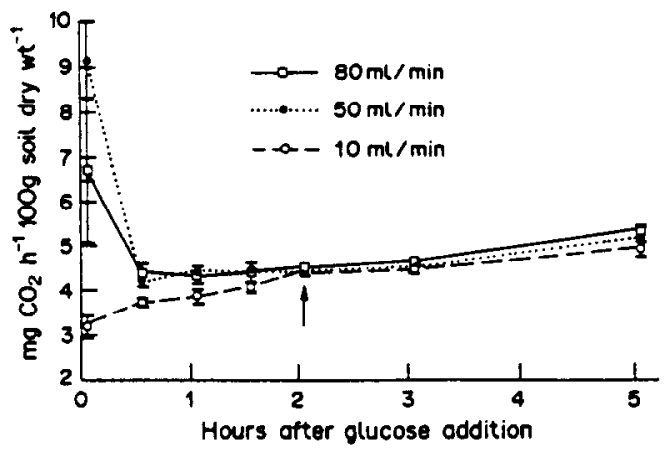

Fig. 3. Stability of the $\mathrm{CO}_{2}$-testing apparatus with different air-flow rates. The arrow shows the time required for an air-flow rate $10 \mathrm{ml} \mathrm{min}^{-1}$ to reach a stable $\mathrm{CO}_{2}$ output rate. Bars are $\pm I S E$.

between $30 \mathrm{~min}$ and $3 \mathrm{~h}$ after glucose addition. This is also true for all the soils we have tested. The problem of instability of $\mathrm{CO}_{2}$ evolution during the early period of incubation found by Anderson and Domsch (1978) does not occur for the kinds of soil we used.

This proposed method for $\mathrm{CO}_{2}$ measurement has several advantages:

(1) It allows measurement of $\mathrm{CO}_{2}$ in a continuous air-flow situation. Martens (1987) has shown that a continuous air-flow is very important for a correct measurement of $\mathrm{CO}_{2}$ evolution from neutral to alkaline soils.

(2) The cost is very low. We estimate that the total cost of a 20-channel apparatus is only about 250-300 US dollars.

(3) It is possible to control $\mathrm{CO}_{2}$ concentration in the air inside the incubator simply by controlling the air-flow rate. This can eliminate any possibilities of either inhibiting SIR due to a very high $\mathrm{CO}_{2}$ concentration or stimulating SIR due to a very low $\mathrm{CO}_{2}$ concentration in the

\begin{tabular}{|c|c|c|c|c|c|}
\hline \multirow{2}{*}{\multicolumn{3}{|c|}{ Soil water content }} & \multicolumn{3}{|c|}{ SIR } \\
\hline & & & \multicolumn{2}{|c|}{ Glucose addition } & \multirow[b]{2}{*}{ Difference } \\
\hline $\begin{array}{c}\text { FWHC } \\
(\%)\end{array}$ & $\begin{array}{l}w / w \\
(\%)\end{array}$ & $W P^{2}$ (bar) & Dry & Wet & \\
\hline $\begin{array}{r}50 \\
70 \\
100 \\
120 \\
150 \\
170 \\
685\end{array}$ & $\begin{array}{r}14.6 \\
20.4 \\
29.2 \\
35.0 \\
43.8 \\
49.6 \\
200.0\end{array}$ & $\begin{array}{l}-8.44 \\
-5.88 \\
-4.15 \\
-2.86 \\
-1.57 \\
-0.28 \\
-5.02\end{array}$ & $\begin{array}{l}2.81(\mathrm{~b})^{3} \\
3.17 \text { (c) } \\
3.40 \text { (d) } \\
3.58 \text { (c) } \\
3.45 \text { (de) } \\
3.26 \text { (c) } \\
0.70 \text { (a) }\end{array}$ & $\begin{array}{l}2.21(\mathrm{~b}) \\
3.17(\mathrm{c}) \\
3.60(\mathrm{~d}) \\
3.81(\mathrm{c}) \\
3.77(\mathrm{c}) \\
3.20(\mathrm{c}) \\
0.74(\mathrm{a})\end{array}$ & $\begin{array}{c}-\cdots \\
\cdots \\
*\end{array}$ \\
\hline
\end{tabular}
air inside the incubator (Macfadyen, 1973; Van Cleve et al., 1979).

(4) It is very easy to operate. No specific skills or sophisticated training is needed.

There are also some disadvantages associated with this method. First of all, the minimum detectable

${ }^{1}$ Percentage field water-holding capacity.

${ }^{2}$ Water potential measured by using a thermocouple psychrometer chamber.

${ }^{3}$ Numbers which have the same letter are not significantly different among water levels at $P<0.05$.

- Significant at $P<0.05$ and "Significant at $P<0.01$ between the two methods of glucose addition. 
level of this method ( $c a 40 \mu \mathrm{g}$ ) is considerably higher than that of the IRGA $(0.31 \mu \mathrm{g})$ or gas chromatography $(3.6 \mu \mathrm{g})$ (Van Cleve et al., 1979). But this problem can be solved by using larger quantities of soil and larger incubation flasks. Secondly, hand titration involved in this method is laborious. In general, the method described above is adequate for routine soil respiration measurement, and especially suitable for uses in SIR measurement.

\section{Effect of soil moisture condition on SIR}

Soil water content during the incubation significantly influences SIR rate $(P<0.01)$ (Table 1). The maximum SIR rates occurred at $120 \%$ field water-holding capacity (FWHC) for both methods of glucose addition. The SIR rates decreased when the soil water contents were either too low or too high. The highest water addition $(200 \% \mathrm{w} / \mathrm{w})$ caused a dramatic decrease of SIR which was only about $19 \%$ of the maximum SIR rate for both methods of glucose addition. When the soil water content is below the optimal level, lower water availability or non-uniform glucose distribution may occur, which may in turn cause a decrease in SIR. When the soil water content is higher than the optimal, the lower oxygen supply may inhibit aerobic activities of microbes, decreasing SIR (Orchard and Cook, 1983; Linn and Doran, 1984a, b). Comparison of SIR rates between the two methods of glucose addition under different water content indicated that the SIR rate of dry addition under the lowest water content $(50 \%$ FWHC) was significantly $(P<0.01)$ higher, probably due to a better glucose distribution under dry addition than wet addition at this soil water content. However, the dry addition produced significantly lower SIR rates than the wet addition when soil water contents were 100,120 and $150 \%$ of FWHC. This may imply a better glucose distribution or less destruction to the soil microbes of wet addition at higher water contents.

The theoretical concept of the SIR technique (Anderson and Domsch, 1978) stated that under identical conditions of incubation, the initial, substrateinduced, maximal respiratory responses (ISIMRR) were correlated to the actual size of the living. non-resting microflora under the assumption that the substrate used was available to the majority of the soil microorganisms. For identical conditions of incubation, soil water is one of the critical factors which must be determined and controlled. Considering the other two prerequisites (ISIMRR and a universal substrate), the soil water condition should be optimized such that an ISIMRR is obtained and the soil water content is suitable for the majority of the soil microorganisms. Therefore, a soil water content of $120 \%$ of FWHC which produces ISIMRR seems to be more appropriate than the approach of $2 \mathrm{ml}$ soil water $\mathrm{g}^{-1}$ oven-dry soil which produces significantly lower values of SIR due to the flooding condition (West and Sparling, 1986) or the original method in which the soil water condition was left uncontrolled (Anderson and Domsch, 1978). Both of the previous methods give significantly lower SIR values for the soil used here. The former is likely to underestimate the aerobic component of the total microbial biomass in favor of anaerobic component. The latter may violate the first prerequisite of identical conditions of incubation.

We found that the modifications of using $120 \%$ FWHC as a standard soil water condition during the incubation. adding glucose in a liquid form, and the continuous air-flow $\mathrm{CO}_{2}$-measurement system offered benefits for use of the SIR technique in a variety of soil studies. By using $120 \%$ FWHC as the standard water condition during the incubation, an initial substrate-induced maximal respiration rate can be measured with accuracy and the prerequisites are better satisfied. Use of the continuous air-flow $\mathrm{CO}_{2}$ measurement system helps to solve the problem of high experimental errors due to the relative distribution of $\mathrm{CO}_{2}$ between liquid phase $\left(\mathrm{HCO}_{3}^{-}\right)$and gaseous phase $\left(\mathrm{CO}_{2}\right)$ for soils with $\mathrm{pH}>6.5$ (Martens, 1987; West and Sparling, 1986), and reduces the danger of possible inhibition or stimulation of SIR due to very high or very low $\mathrm{CO}_{2}$ concentration in the headspace of the incubator.

Acknowledgements-We thank Drs Paul Hendrix and David Wright and Mr Michael Beare for their constructive suggestions, and Drs Peter Hartel and Märshall Darley and Mr Mamdouh El-Amry for use of their equipment. This research was supported by a National Science Foundation Grant to the University of Georgia.

\section{REFERENCES}

Anderson J. P. E. and Domsch K. H. (1978) A physiological method for the quantitative measurement of microbial biomass in soil. Soil Biology \& Biochemistry 10, 215-221.

Edwards N. T. (1982) A timesaving technique for measuring respiration rates in incubated soil. Soil Science Sociely of America Journal 46, 1114-1116.

Groffman P. M. (1985) Nitrification and denitrification in conventional and no-tillage soils. Soil Science Society of America Journal 49, 329-334.

Jenkinson D. S. and Ladd J. N. (1981) Microbial biomass: measurement and turnover. In Soil Biochemistry, Vol. 5 (E. A. Paul and J. N. Ladd, Eds), pp. 415-417. Marcel Dekker, New York.

Linn D. M. and Doran J. W. (1984a) Aerobic and anaerobic microbial populations in no-till and plowed soil. Soil Science Society of America Journal 48, 794-799.

Linn D. M. and Doran J. W. (1984b) Effect of water-filled pore space on carbon dioxide and nitrous oxide production in tilled and nontilled soils. Soil Science Society of America Journal 48, 1257-1272.

Macfadyen A. (1973) Inhibitory effects of carbon dioxide on microbial activity in soil. Pedobiologia 13, 140-149.

Martens R. (1987) Estimation of microbial biomass in soil by the respiration method: importance of soil $\mathrm{pH}$ and flushing methods for the measurement of respired $\mathrm{CO}_{2}$. Soil Biology \& Biochemistry 19, 77-81.

Orchard V. A. and Cook F. J. (1983) Relationship between soil respiration and soil moisture. Soil Biology \& Biochemistry 15, 447-454.

Van Cleve K., Coyne P. I., Goodwin E., Johnson C. and Kelley M. (1979) A comparison of four methods for measuring respiration in organic material. Soil Biology \& Biochemistry 11, 237-246.

West A. W. and Sparling G. P. (1986) Modifications to the substrate-induced respiration method to permit measurement of microbial biomass in soils of differing water contents. Journal of Microbiological Methods 5, 177-189. 